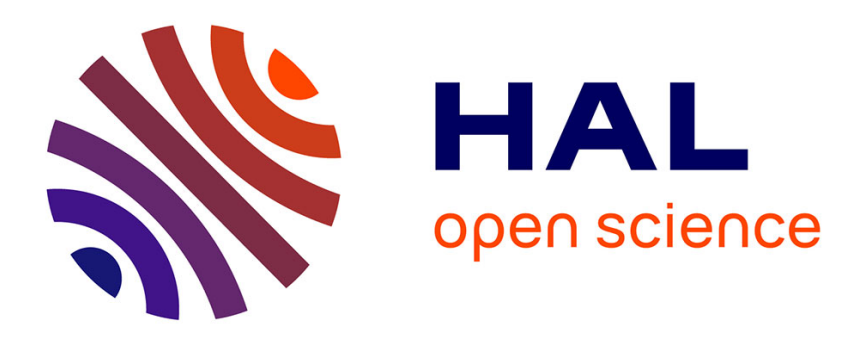

\title{
Analysis of slug-tests with high-frequency oscillations
}

Olivier Audouin, Jacques Bodin

\section{To cite this version:}

Olivier Audouin, Jacques Bodin. Analysis of slug-tests with high-frequency oscillations. Journal of Hydrology, 2007, 334, pp.282-289. 10.1016/j.jhydrol.2006.10.009 . hal-00260614

\section{HAL Id: hal-00260614 https://hal.science/hal-00260614}

Submitted on 4 Mar 2008

HAL is a multi-disciplinary open access archive for the deposit and dissemination of scientific research documents, whether they are published or not. The documents may come from teaching and research institutions in France or abroad, or from public or private research centers.
L'archive ouverte pluridisciplinaire HAL, est destinée au dépôt et à la diffusion de documents scientifiques de niveau recherche, publiés ou non, émanant des établissements d'enseignement et de recherche français ou étrangers, des laboratoires publics ou privés. 


\title{
Analysis of slug-tests with high-frequency oscillations
}

\author{
by Olivier Audouin ${ }^{1,2,3}$ and Jacques Bodin ${ }^{1,2}$ \\ ${ }^{1}$ Université de Poitiers, FRE 3114 HydrASA, 40 av. Recteur Pineau, 86022 Poitiers Cedex, France \\ ${ }^{2}$ CNRS/INSU, FRE 3114 HydrASA, 40 av. Recteur Pineau, 86022 Poitiers Cedex, France \\ ${ }^{3}$ Now at SEMM LOGGING, Les Maufras, 18360 Vesdun, France
}

\begin{abstract}
Extensive slug-test experiments have been performed at the Hydrogeological Experimental Site (HES) of Poitiers in France, made up of moderately fractured limestones. All data are publicly available through the "H+" database, developed within the scope of the ERO program (French Environmental Research Observatory, http://hplus.ore.fr). Slug-test responses with high-frequency ( $>0.12 \mathrm{~Hz})$ oscillations have been consistently observed in wells equipped with multiple concentric casing. These oscillations are interpreted as the result of inertia-induced fluctuations of the water level in the annular space between the inner and outer casing. In certain cases, these high-frequency oscillations overlap with lower frequency $(<0.05 \mathrm{~Hz})$ oscillations, which leads to complex responses that cannot be interpreted using conventional models. Slug-test data have been processed in the Fourier-frequency domain, in order to remove the high-frequency component by a signal-filtering method. The corrected signals have been interpreted with the model of (McElwee and Zenner, 1998), which accounts for the inertia of the water-column above the well screen, non-linear head losses in the well, and neglects the aquifer storage (quasi-steady-state approximation). Hydraulic conductivity values interpreted from dual-frequency slug-tests compare well to those interpreted from "standard" overdamped or underdamped slug-test responses.
\end{abstract}

\section{Introduction}

Slug testing is a common field method for estimating aquifer permeability. It consists in inducing an abrupt change in water level in a well and monitoring the subsequent water level recovery. In highly permeable aquifers and/or deep wells, the abrupt pressure change in the test well may result in 
oscillations of the water level about the equilibrium level. Such slug-tests are generally said to be underdamped and the oscillations are interpreted as caused by the inertia of the water column above the well screen (or open borehole), see e.g. (Butler, 1997). Since the work by (Van Der Kamp, 1976), a number of theoretical models accounting for inertial effects have been developed for the analysis of underdamped slug-tests, see e.g. refs. in (Butler, 1997; McElwee, 2002). In the Hydrogeological Experimental Site (HES) of Poitiers in France, two types of slug-test oscillations have been consistently observed: (1) low-frequency ( $<0.05 \mathrm{~Hz}$ ) oscillations that rapidly vanish, and (2) high-frequency $(>0.12 \mathrm{~Hz}$ ) oscillations with a slow damping. The two types of oscillations overlap in certain wells, which leads to complex responses that cannot be interpreted using conventional models. In this paper, we introduce a signal processing method that enables to filter the oscillations according to their frequency signature. It will be shown that the removal of high-frequency (HF) oscillations yields a signal that can be interpreted with the model of (McElwee and Zenner, 1998), which accounts for the inertia of the water-column above the well screen, non-linear head losses in the well, and neglects the aquifer storage (quasi-steady-state approximation).

\section{Slug test experiments}

The Hydrogeological Experimental Site (HES) is located 2-km southeast from Poitiers, France. The studied aquifer is made up of moderately fractured limestones $100 \mathrm{~m}$ thick, overlain by a 5-20 m thick clay unit. Twenty-five fully penetrating wells of large diameter (0.23 m at $120-\mathrm{m}$ depth) were drilled between 2002 and 2004. The wells are located according to a geometric pattern of symmetry 4, inspired from the classic "five-spot" well configuration used in oilfield production. This geometric well array occupies a square area of $210 \mathrm{~m}$ x $210 \mathrm{~m}$. The wells were cased with 0.24 -m-diameter steel pipe to depths ranging from $15 \mathrm{~m}$ to $80 \mathrm{~m}$. Below the steel casing, certain wells were left uncased while others were partly or fully screened with 0.17 -m-diameter machine-slotted PVC to prevent a risk of collapse (Fig. 1). The PVC pipes are either suspended to the steel casing or rest on the borehole bottom. They have not been sealed to the outer steel casing so that they can be removed for further optical investigations such as borehole-camera logging. In natural undisturbed groundwater conditions, the water table in wells ranges between $18 \mathrm{~m}$ and $25 \mathrm{~m}$ below the ground surface. The 
overall research objective related to this site is to improve the understanding of flow and solute transport in calcareous aquifers, down to depths planned for drinking and/or agricultural water supply. Preliminary studies have shown that flow is mainly located in a few horizontal features interpreted as bedding planes, which are hydraulically connected by subvertical fractures. One of the specific research topics explored in the HES is the investigation of spatial variability of hydrodynamic parameters by multiple hydraulic-tests in the geometric well array (Delay et al., 2004). As a part of this study, a large number of slug tests (about 100) were performed in order to estimate the hydraulic conductivity of the aquifer in the vicinity of boreholes. The slug tests were performed after an important series of pumping tests, which ensured that each well was properly developed. The slug tests were initiated by a sudden release of water in the inner casing (falling-head initiation), with the help of a $3 \mathrm{~m}^{3}$ capacity tank equipped with a rapid flow valve. Experiments were conducted following the recommendations by (McElwee, 2002) and (Butler et al., 2003): (1) in each well, multiple slug tests involving various initial head displacements (injection of various volumes of water) were performed to test for repeatability and nonlinear effects, and (2) for each slug test, the water-level recovery was monitored over time with a pressure transducer placed within $0.5 \mathrm{~m}$ below the static level, which minimised the errors in measured heads caused by the acceleration of the water column. Head data were recorded with a $2 \mathrm{~Hz}$ frequency data logger. All slug-test data are publicly available through the "H+" database, developed within the scope of the ERO program (French Environmental Research Observatory, http://hplus.ore.fr), see (de Dreuzy et al., 2006). Fig. 2 illustrates the 4 typical behaviours of slug-test responses obtained in the HES: standard-overdamped behaviour (no oscillation), standard-underdamped behaviour with low-frequency $(<0.05 \mathrm{~Hz})$ oscillations, overdamped responses with high-frequency $(>0.12 \mathrm{~Hz}$ ) oscillations, and underdamped responses combining both low-frequency and high-frequency oscillations.

\section{Interpretation of high-frequency oscillations}

For an inertial system, the oscillation damping and frequency are directly related to the effective length $L_{e}$ of the water column involved in the slug test (Butler, 1997): 


$$
L_{e} \approx \frac{g\left(t_{n+1}-t_{n}\right)^{2}}{4 \pi^{2}+\left[\ln \left(W_{n} / W_{n+1}\right)\right]^{2}}
$$

where $g$ is the acceleration of gravity, $t_{n}$ and $W_{n}$ are the time and amplitude of the $n$th peak in the slug response, respectively. Analysis of HES slug-test oscillations with the above formula yields $L_{e}$ values of the order of $10 \mathrm{~m}$ for high-frequency oscillations, and $130 \mathrm{~m}$ for low-frequency oscillations. Several authors propose theoretical definitions of the effective column length of $L_{e}$, based on geometrical considerations about the well casing/screen system (see the review by (Butler, 1997)). Although the definitions of $L_{e}$ vary according to authors, $L_{e}$ values should always be larger than the length of the water column above the well screen plus one-third of the screen length. For the HES wells, $L_{e}$ values should thus be systematically larger than $50 \mathrm{~m}$. The value $L_{e} \approx 130 \mathrm{~m}$ calculated from low-frequency oscillations in slug-test data is consistent with this lower bound, but the value $L_{e} \approx 10 \mathrm{~m}$ cannot be related to the inertia of the water column in the well. It must also be noted that high-frequency oscillations occur only in wells equipped with multiple concentric casing at the depth of the static piezometric level. Therefore, it is very likely that high-frequency oscillations result from inertiainduced fluctuations of the water level in the annular space between the inner-PVC casing and outersteel casing (see Fig. 3). Before the slug-test initiation, the water level in the well annulus is at equilibrium with, on the one hand, the water level in the inner PVC casing and, on the other hand, the hydraulic head in the aquifer. During a slug test, a volume of water injected in the inner casing will flow to the well annulus before flowing into the aquifer. If the momentum of the injected water column is great enough, more water flows to the well annulus than what can flow into the aquifer. This results in head differences between the inner casing and the well annulus, which progressively return to equilibrium according to damped oscillatory fluctuations. Similar perturbations where reported by (Shapiro and Hsieh, 1998) for slug tests performed between packers. As these high-frequency oscillations do not contain any information about the aquifer properties, they may be removed from the slug-test responses to make the interpretation easier. In the next section, we describe how the HES slug-test data have been filtered using a signal-processing technique. 


\section{Filtering of slug-test data}

In order to remove the undesirable oscillations from the slug-test responses, the measured data have been processed in the Fourier-frequency domain. The first step consists in performing a discrete Fourier transform (DFT) on water level data. The resulting frequency spectrum allows determining precisely the frequency of the undesirable oscillations. For the example illustrated in Fig. 4, the highfrequency oscillations are represented by the narrow peak centred on $0.14 \mathrm{~Hz}$. The other peak represents the frequency of the underdamped signal. The whole HES slug-test data set shows highfrequency components ranging between 0.13 and $0.16 \mathrm{~Hz}$.

In the time domain, the filtering of a discrete signal $i(t)$ may be described by the convolution principle:

$$
o(t)=\sum_{k=0}^{n} i(k) h(t-k)
$$

where $o(t)$ is the output-filtered signal, $n$ is the number of data in the input signal, and $h(t)$ is the impulse response of the filter. The equivalent expression of (1) in the z-transform domain (i. e. discrete equivalent of the Laplace transform) writes:

$$
O(z)=I(z) H(z)
$$

where $O(z), I(z)$ and $H(z)$ correspond to the z transforms of $o(t), i(t)$ and $h(t)$, respectively. The filter applied to HES slug-test data is a filter band suppressor of second order. Its transfer function $\mathrm{H}(\mathrm{z})$ writes:

$$
H(z)=K \frac{1-2 \cos \theta z^{-1}+z^{-2}}{1-2 \rho \cos \theta z^{-1}+\rho^{2} z^{-2}}
$$

where:

$$
\begin{gathered}
K=\frac{1-2 \rho \cos \theta+\rho^{2}}{2-2 \cos \theta} \\
\theta=\frac{2 \pi \omega_{0}}{\omega_{i}}
\end{gathered}
$$

where $\omega_{0}\left[\mathrm{~T}^{-1}\right]$ is the peak frequency to be suppressed, $\omega_{i}\left[\mathrm{~T}^{-1}\right]$ is the sampling frequency of the input signal, and $\rho$ is an adimensionnal parameter that controls the filter width in the frequency domain. The 
width of the frequency interval for which the filtering rate is greater than $30 \%$ (band suppressed at $3 \mathrm{~dB}$ ) is given by:

$$
\Delta \omega=(1-\rho) \frac{\omega_{e}}{\pi}
$$

The value of $\rho$ must be less than 1 for theoretical reasons but larger than 0,8 for practical reasons: $\rho$ values lower than 0.8 may amplify the high-frequency noise and distort the signal component of interest (overdamped or underdamped slug-test response). The shape of the filter in the frequency domain is shown in Fig. 5, for $\rho=0.9$ and $\omega_{0}=0.1406 \mathrm{~Hz}$. All HES slug-test data with high-frequency oscillations have been processed with $\rho$ values ranging between 0.85 and 0.95 . Discrete Fourier transform and signal-filtering have been processed with MATLAB ${ }^{\circledR}$. An example of filtering of underdamped slug-test is shown in Fig. 6.

\section{Slug-test interpretation}

Most of the slug-test models proposed in the literature assume homogeneous aquifer properties. This assumption is probably erroneous for the HES aquifer because borehole imaging, geophysical logging and core data indicate that flow is mainly located in a few horizontal features interpreted as bedding planes, which are hydraulically connected by subvertical fractures. Specific models have been developed for interpreting slug tests performed in fractured formations, see e.g. (Barker and Black, 1983; Karasaki et al., 1988). As compared to conventional models, these models involve additional parameters such as the number and precise characteristics of the fracture flowpaths (discrete fracture approach), and/or parameters that characterise the storage and fluid exchange properties of the fracture-matrix system (double-porosity approach). As noted by (Butler, 1997) and (Lee and Lee, 1999), these models are of little use in practice because most of these additional parameters cannot be reliably measured in the field and must be adjusted. As an illustration, the above-mentioned borehole geophysical data available at the HES are not sufficient to describe the geometrical characteristics and hydraulic properties of the identified fracture flowpaths. The multiplication of fitting parameters in discrete-fracture models or double-porosity models raises the classic problem of nonuniqueness. Both (Barker and Black, 1983) and (Karasaki et al., 1988) acknowledge that many combinations of model 
parameters may lead to similar responses in their respective models. Although fractured aquifers are inherently heterogeneous, the use of homogeneous models involving a reduced number of parameters may thus be considered as a practical alternative. Furthermore, (Shapiro and Hsieh, 1998) have shown that the interpretation of slug tests conducted in fractured rocks with a homogeneous model may yield bulk-transmissivity values within an order of magnitude of those estimated with more detailed investigations based on fluid-injection tests in short borehole intervals isolated between packers. The homogeneous approach will thus be adopted to analyse HES slug-test data, in order to get order-ofmagnitude estimates of the bulk transmissivity in the vicinity of boreholes.

As shown in Fig. 7 for well M03, normalised slug-test responses do not coincide for various initial head displacements. This indicates that slug-test responses are influenced by nonlinear effects, which have to be considered in data interpretation. A suited model is that of (McElwee and Zenner, 1998), which accounts for nonlinear head loss and inertial effects in the tested well. This model assumes that flow in the aquifer may be described by the (Hvorslev, 1951) model, in which the aquifer storage is neglected (quasi-steady-state approximation). According to (McElwee, 2002), this assumption may be tested by plotting slug data in the usual (Hvorslev, 1951) semilog format as illustrated in Fig. 7. In such a representation, nonlinear effects are indicated by a downward curvature (McElwee, 2000), whereas storage effects yield upward curvature (Butler, 1997; McElwee, 2000). Such upward curvature does not occur for HES slug-data, which either fit a straight line or show a downward curvature. The quasi-steady-state assumption thus appears as reasonable. The general equation for the model developed by (McElwee and Zenner, 1998) is given by:

$$
\underbrace{\left(h+b+z_{0}+\beta\right) \frac{d^{2} h}{d t^{2}}}_{\text {inertial term }}+\underbrace{A\left|\frac{d h}{d t}\right| \frac{d h}{d t}}_{\text {nonlinearity }}+\frac{g \pi r_{c}^{2}}{F K}\left(\frac{d h}{d t}\right)+g h=0
$$

where $h$ is the water level in the well above the static level, $b$ is the length of the well screen, $z_{0}$ is the length of the water column above the well screen, $\beta$ is a parameter related to the effective length of the water column involved in the slug test (taking into account the radius changes in the water column), $A$ is the nonlinear parameter related to the water velocity in the well bore, $F$ is the (Hvorslev, 1951) form factor, and $K$ is the hydraulic conductivity. There is no analytical solution to the above equation, 
which has to be solved numerically. A finite difference method has been implemented by (McElwee, 2000) in the NLSLUG program. The program has 4 fitting parameters: $\beta, A, K$, and $V_{0}$ the initial velocity of the water column at slug initiation. As illustrated in Fig. 8, the model enables to fit properly the various types of HES slug-test responses. The parameter values used to fit the whole slugtest data set are summarised in Table 1. Hydraulic conductivities obtained from signal-filtered data range between $2.6 \times 10^{-5}$ and $1.3 \times 10^{-4} \mathrm{~m} / \mathrm{s}$. These K-values are of the same order of magnitude as those obtained from the interpretation of "standard" overdamped or underdamped slug-test responses monitored in uncased wells M01, M03, M11, M16 and M19 (K-values ranging between $2.6 \times 10^{-5}$ and $\left.7.3 \times 10^{-4} \mathrm{~m} / \mathrm{s}\right)$. The uncased wells M09 and M17 show lower K-values $\left(2.5 \times 10^{-6}\right.$ and $2.9 \times 10^{-6} \mathrm{~m} / \mathrm{s}$, respectively) but borehole geophysical data indicate that these two wells do not intercept any fracture flow path, unlike other tested wells.

\section{Summary and Conclusions}

Slug tests performed in wells equipped with multiple-concentric casing may be affected by inertiainduced water level fluctuations in the annular space between the inner and outer casings. These fluctuations lead to oscillations of the water level in the slugged well. In formations of high hydraulic conductivity and/or deep wells, these oscillations may overlap with lower frequency oscillations resulting from inertia effects involving the whole water column above the well screen. Such dualfrequency oscillations have been observed at the Hydrogeological Experimental Site (HES) of Poitiers in France, where a limestone aquifer is currently being investigated for research purposes. In this paper, we show how the high-frequency component may be removed from slug-test responses by a signal-filtering method. Slug-test data are processed in both the Fourier-frequency domain and the time domain. The filtered signal may then be analyzed with conventional slug-test models. The nonlinear model of (McElwee and Zenner, 1998) has been chosen to analyse the HES slug-test data, because of the dependence on initial head displacement observed in slug-induced responses. The interpretation of slug-test performed at the HES is based on a homogeneous approach, which is assumed to be adequate in providing order-of-magnitude estimates of the hydraulic conductivity in the vicinity of boreholes. Hydraulic conductivity values interpreted from dual-frequency slug-tests 
compare well to those interpreted from "standard" overdamped or underdamped slug-test responses.

The signal-filtering method proposed in this work may thus be useful to facilitate the interpretation of slug tests performed in multi-cased wells.

Acknowledgments. We are grateful to the "Poitou-Charentes Water Research Program" (XIIe CPER), the "French Environmental Research Observatory" (ERO) program, and the "French National Program for Research in Hydrology” for their financial support of this work.

\section{References}

Barker, J.A. and Black, J.H., 1983. Slug tests in fissured aquifers. Water Resources Research, 19(6): 1558-1564.

Butler, J.J., Jr., 1997. The design, performance, and analysis of slug tests. Lewis Publishers, 252 pp.

Butler, J.J., Jr., Garnett, E.J. and Healey, J.M., 2003. Analysis of slug tests in formations of high hydraulic conductivity. Ground Water, 41(5): 620-630.

de Dreuzy, J.-R. et al., 2006. General database for ground water site information. Ground Water, accepted for publication.

Delay, F., Porel, G. and Bernard, S., 2004. Analytical 2D model to invert hydraulic pumping tests in fractured rocks with fractal behavior. Geophysical Research Letters, 31.

Hvorslev, M.J., 1951. Time lag and soil permeability in ground-water observations. 36, US Army Corps of Engineers, Waterways Experiment Station, Vicksburg, MS.

Karasaki, K., Long, J.C.S. and Witherspoon, P.A., 1988. Analytical models of slug tests. Water Resources Research, 24(1): 115-126.

Lee, J.Y. and Lee, K.K., 1999. Analysis of the quality of parameter estimates from repeated pumping and slug tests in a fractured porous aquifer system in Wonju, Korea. Ground Water, 37(5): 692-700.

McElwee, C.D., 2000. Implementation of a nonlinear model for analysis of slug tests. 2000-01, Kansas Geological Survey.

McElwee, C.D., 2002. Improving the analysis of slug tests. Journal of Hydrology, 269: 122-133.

McElwee, C.D. and Zenner, M., 1998. A nonlinear model for analysis of slug-test data. Water Resources Research, 34(1): 55-66.

Shapiro, A.M. and Hsieh, P.A., 1998. How good are estimates of transmissivity from slug tests in fractured rock ? Ground Water, 36(1): 37-48.

Van Der Kamp, G., 1976. Determining aquifer transmissivity by means of well response tests: the underdamped case. Water Resources Research, 12(1): 71-77. 


\section{Figure and Table captions}

Fig. 1. Typical construction diagrams of HES wells.

Fig. 2. Typical slug-test responses in HES wells. A: "standard" overdamped response; B: "standard" underdamped response with low-frequency oscillations; C: overdamped response with high-frequency oscillations; D: underdamped response with dual-frequency oscillations.

Fig. 3. Interpretation of high-frequency oscillations: inertia-induced water level fluctuations in the annular space between the inner PVC casing and the outer steel casing.

Fig. 4. Frequency spectrum of the slug-test response in HES well M05, for an initial head displacement $\mathrm{H}_{0}=0.2 \mathrm{~m}$ (slug-test reference = STM5_02).

Fig. 5. Filter shape in the frequency domain for $\rho=0,9$.

Fig. 6. Filtering of high-frequency oscillations: example of processing of the slug test STM5_02 (HES well M05, initial head displacement $\mathrm{H}_{0}=0,2 \mathrm{~m}$ ).

Fig. 7. Slug-test responses (Hvorslev-format plot) in HES wells M01 and M11, for various initial head displacements $\mathrm{H}_{0}$.

Fig. 8. Curve fitting of HES slug-test responses with the model of (McElwee and Zenner, 1998).

Table 1. Interpretation of HES slug tests with the model of (McElwee and Zenner, 1998): fitted parameters. 
Fig. 1.
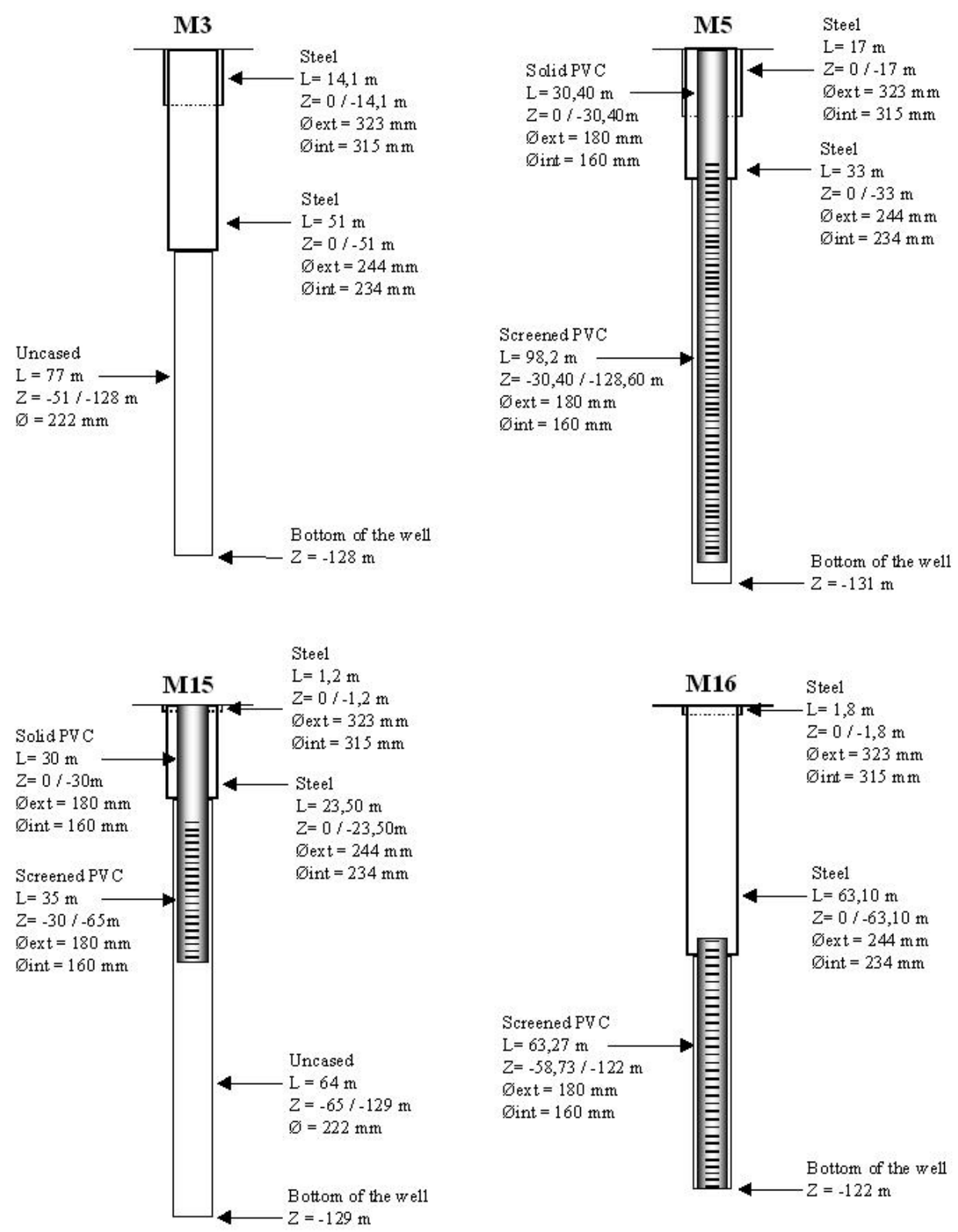
Fig. 2.
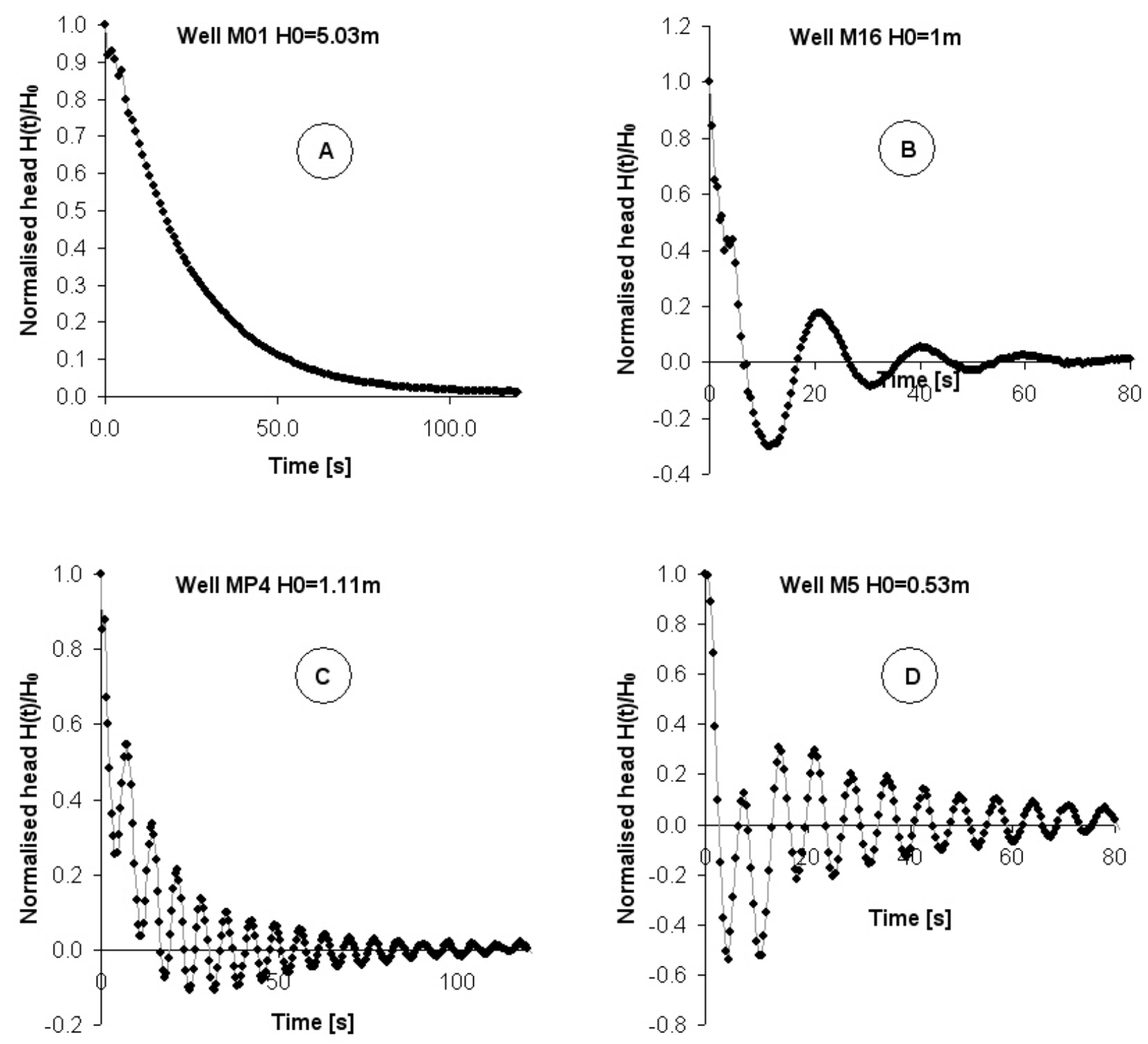
Fig. 3.

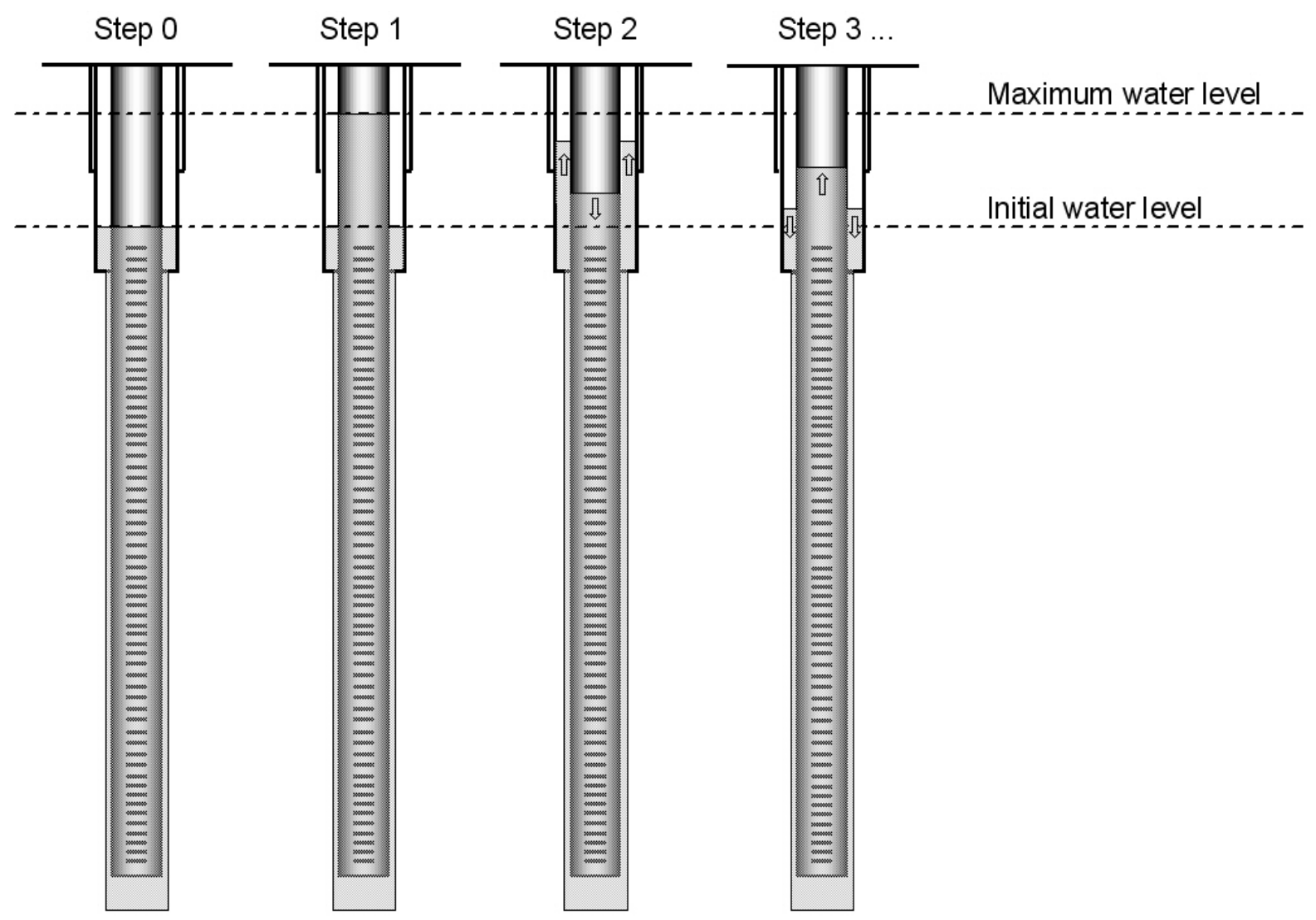

Fig. 4.

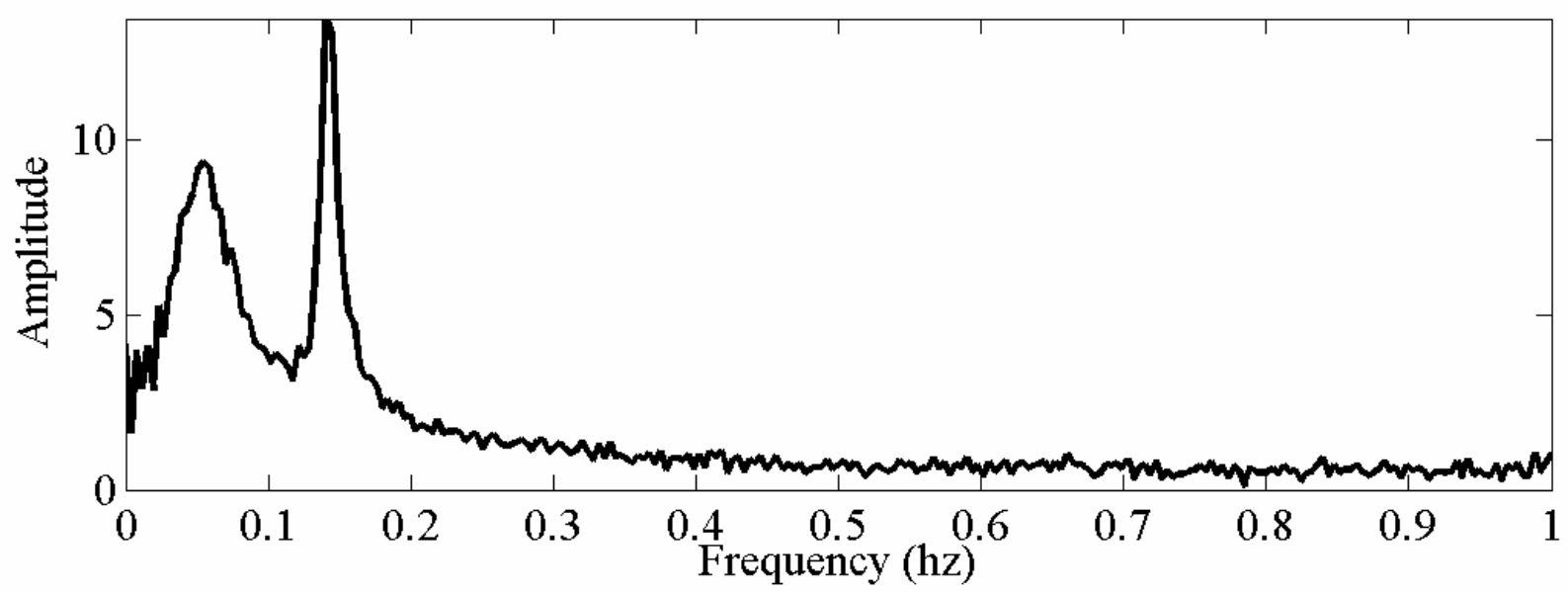


Fig. 5.

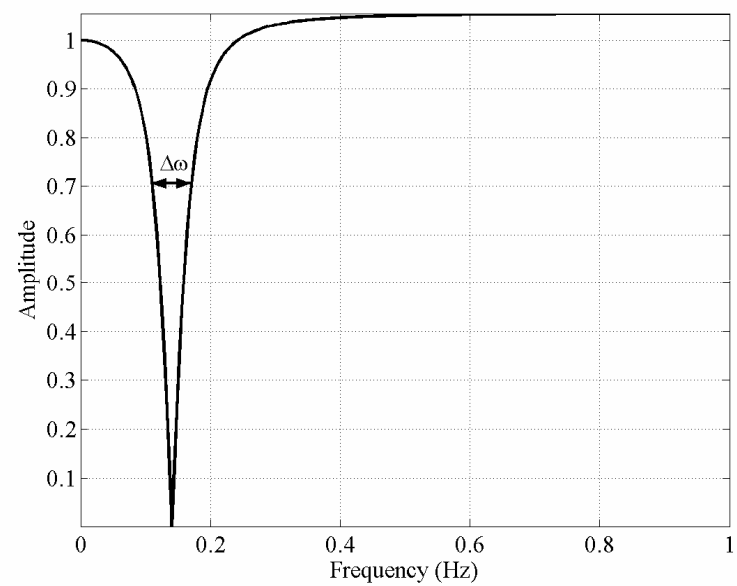

Fig. 6.
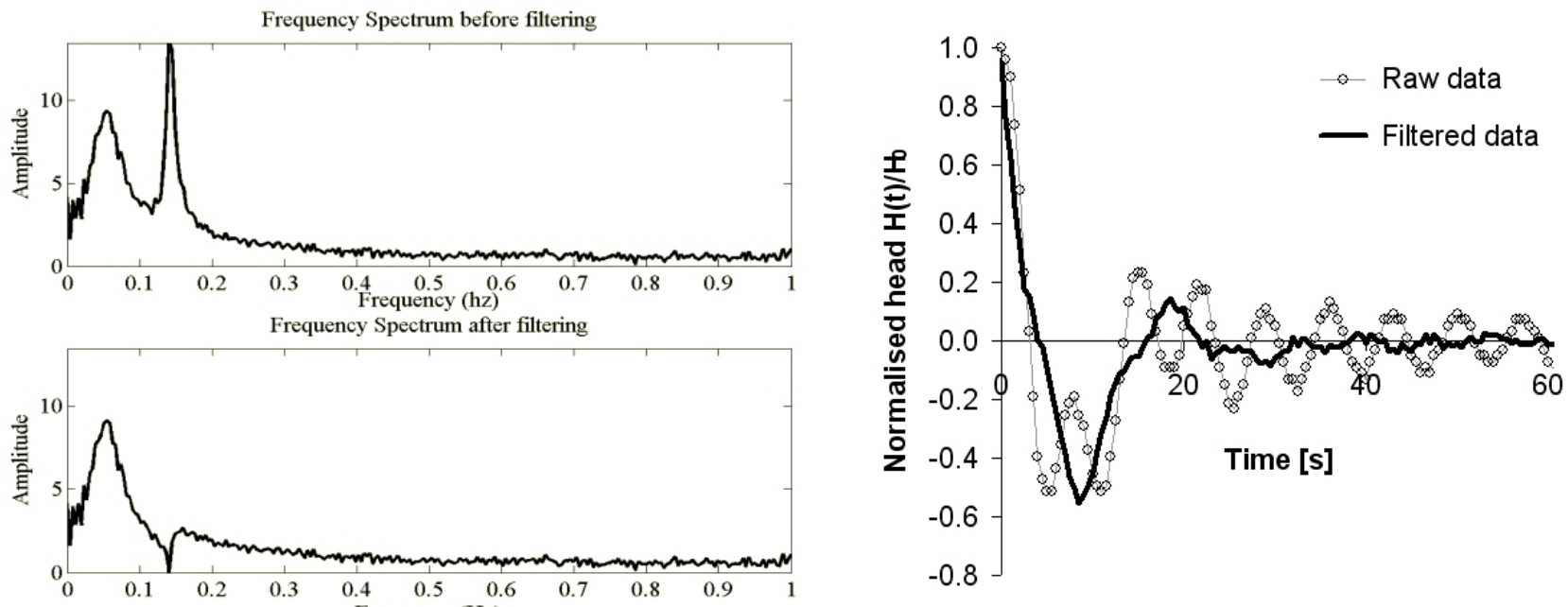
Fig. 7.

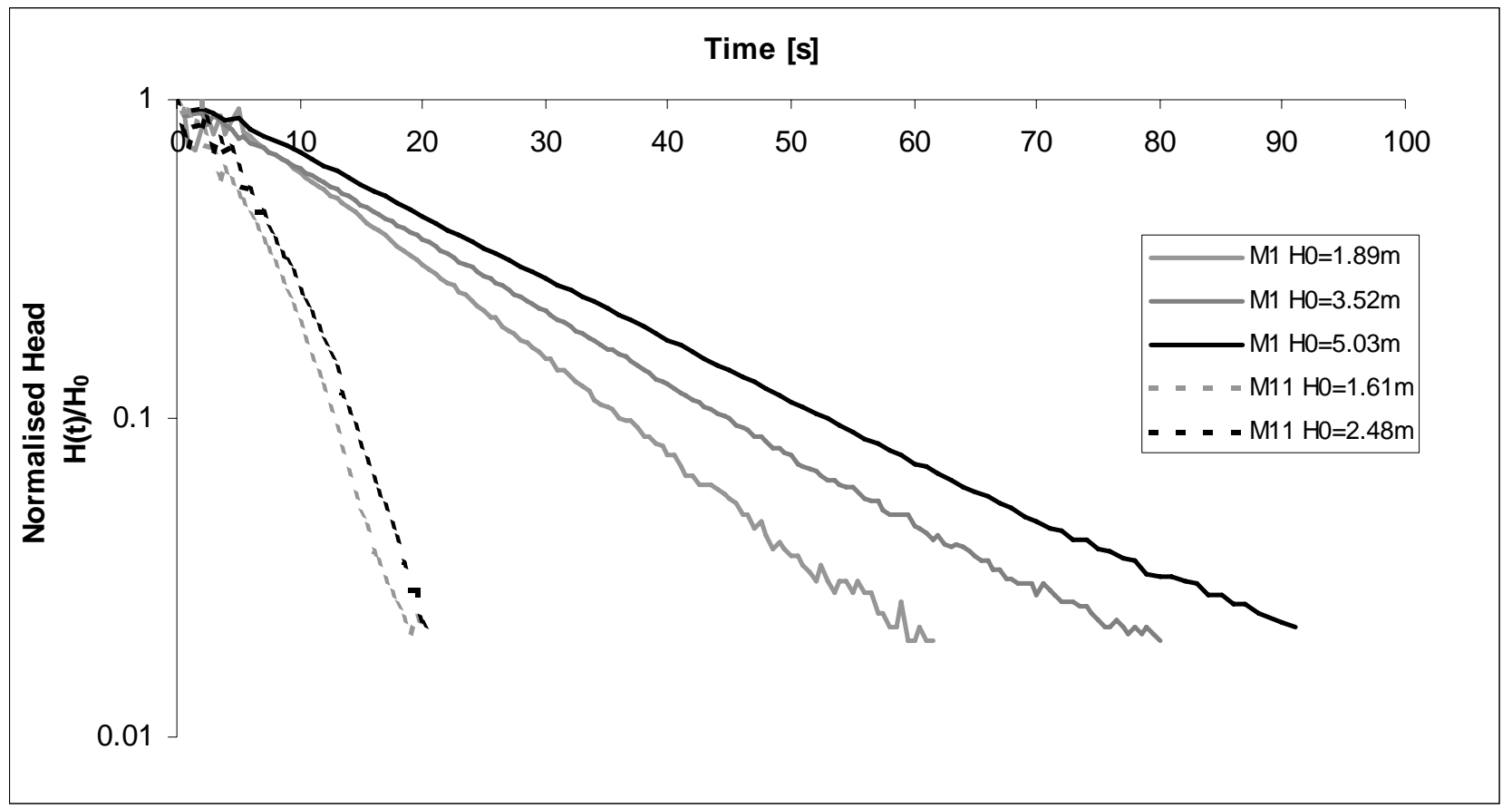


Fig. 8.
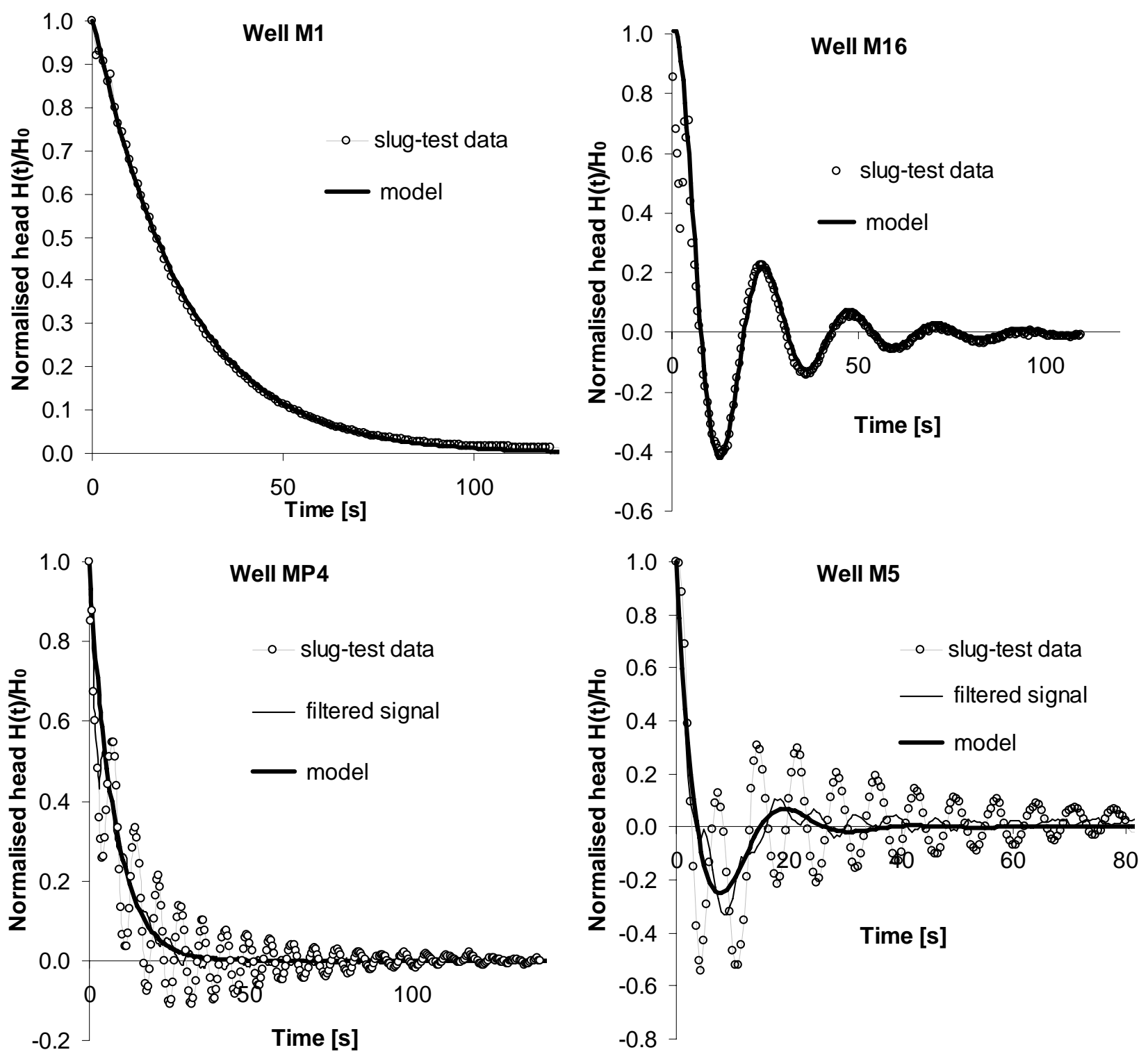
Table 1.

\begin{tabular}{cccccc}
\hline Puits & Casing & $\mathbf{K}[\mathrm{m} / \mathbf{s}]$ & $\beta[\mathbf{m}]$ & $\mathbf{A}[-]$ & $\mathbf{V}_{\mathbf{0}}[\mathrm{m} / \mathbf{s}]$ \\
\hline M01 & single & $2.6 \mathrm{E}-05$ & 0.0 & 170.2 & -0.05 \\
M03 & single & $4.3 \mathrm{E}-05$ & 0.0 & 70.3 & -0.20 \\
M05 & mutiple & $1.3 \mathrm{E}-04$ & 0.0 & 109.6 & -0.15 \\
M09 & single & $2.5 \mathrm{E}-06$ & 0.0 & 0.0 & 0.00 \\
M11 & single & $1.5 \mathrm{E}-04$ & -32.1 & 206.8 & -0.05 \\
M15 & multiple & $5.1 \mathrm{E}-05$ & 0.0 & 303.3 & 0.00 \\
M16 & single & $7.3 \mathrm{E}-04$ & -5.3 & 58.2 & -0.02 \\
M17 & single & $2.9 \mathrm{E}-06$ & 0.0 & 0.0 & -0.01 \\
M19 & single & $6.4 \mathrm{E}-04$ & 26.8 & 67.6 & -0.12 \\
MP4 & multiple & $2.6 \mathrm{E}-05$ & 0.0 & 354.5 & -0.07 \\
\hline
\end{tabular}

